\title{
The Primary and Final Outcomes of Endoscopic and External Dacryocystorhinostomy for Treating Dacryocystitis: A Retrospective Multicenter Study
}

\begin{abstract}
Wenshuang Xu' ${ }^{1,2,5}$, Jianqi Xiao ${ }^{1}$, Yongjie Zhang ${ }^{3}$, Yunhai $\mathrm{Tu}^{4}$, Xiaofeng Zhang1 ${ }^{1}$ Xiaoxia $\mathrm{Wu}^{2}$, Jinglin $\mathrm{Cui}^{1}$, Jing $\mathrm{Li}^{5}$, Monica M Jablonski ${ }^{6}$, Weikuan $\mathrm{Gu}^{5}$, Yan Jiao ${ }^{5 *}$ and Hong Chen ${ }^{1 *}$
\end{abstract}

${ }^{1}$ Center of Integrative Research, The first Hospital of Qiqihar City, China

${ }^{2}$ Department of Ophthalmology, Qiqihar Wuguan Hospital, China

${ }^{3}$ Department of Ophthalmology, Jiaxing Traditional Chinese Medicine Hospital, China

${ }^{4}$ Department of Orbital and Oculoplastic Surgery, Eye Hospital of Wenzhou Medical University, China

${ }^{5}$ Department of Orthopedic Surgery and BME-Campbell Clinic, University of Tennessee Health Science Center, USA

${ }^{6}$ Department of Ophthalmology, University of Tennessee Health Science Center, USA

*Corresponding author: Yan Jiao, Department of Orthopedic Surgery, University of Tennessee Health Science Center, USA

Hong Chen, Center of Integrative Research, The First Hospital of Qiqihar City, China

Received: 阱June 07, 2019

Published: 䟧June 14, 2019

\begin{abstract}
Purpose: To compare the effect of endoscopic and external dacryocystorhinostomy (EN and EX-DCR) for treating dacryocystitis in Chinese adult population.

Methods: A retrospective, multi-center case series was conducted. A total of 185 eyes out of 167 patients suffered from either chronic or acute dacryocystitis were enrolled in this study. Patients were treated in one of the three regional hospitals from January to December of 2016. The patients were reviewed for demographic characteristics, clinical presentation, and management outcome. The primary surgery success was defined as having an anatomical success without any revision surgery. The final surgery success was defined as having an anatomical success after all surgeries (including repeated surgeries).

Results: Enrolled patients included a total of 112 eyes out of 102 patients who underwent EN-DCR, and 73 eyes out of 65 patients who accepted EX-DCR. The primary surgery success rate was 89.29\% (100/112) for EN-DCRs and 89.04\% (65/73) for EX-DCRs. The Kaplan-Meier survival analysis showed no statistical difference in primary surgical outcomes between these two approaches, with a log rank X2 of $0.369(\mathrm{P}=0.543)$. Repeated EN-DCR was accepted by the patients with primary surgical failures in both EN- DCR (12/12) and EX-DCR (8/9) groups, leading the final surgical success rate of the EN-DCR and EX-CR group at $97.32 \%$ and $97.26 \%$, respectively. The final surgical success rate was statistically significantly higher than the primary success rate in each group.

Conclusion: N-DCR is a valid alternative to external procedure in the management of dacryocystitis in the Chinese adult population, because of the comparable primary success rate to external approach and the unique advantages in treating the patients that need repeated surgeries.
\end{abstract}

Keywords: Endoscopic dacryocystorhinostomy; External dacryocystorhinostomy; Primary outcomes; Final outcomes Multicenter study

\section{Introduction}

Dacryocystitis is characterized as an inflammatory state of the nasolacrimal sac. It is classified as acute and chronic status [1]. Patients with chronic dacryocystitis suffer with epiphora and purulent discharge from the punctum, which often is the result from obstruction of the nasolacrimal duct. Chronic dacryocystitis rarely undergoes spontaneous resolution, therefore often brings about a series of long, painful experiences for the patients. If acute 
infection occurs, rapid onset of pain, erythema, swelling, epiphora and a painful area of induration overlying the nasolacrimal sac will appear, which indicates acute dacryocystitis [2]. Dacryocystitis, either chronic or acute, causes patients to suffer significant discomfort and has negative effects on their everyday life. Dacryocystorhinostomy (DCR), one of the major methods to treat dacryocystitis, is a procedure used to create a lacrimal drainage pathway into the nasal cavity. This procedure can reestablish permanent [3]. Two approaches of DCR have been established, endoscopic and external DCR (EX-DCR and EN-DCR). EX-DCR is accomplished through a medial canthal skin incision near the lacrimal sac. It is the traditional treatment of dacryocystitis with a success rate varying from 70 to $99 \%$ [4-7]. However, it has the disadvantages of facial scarring, excessive intra-operative bleeding and disruption of the medial canthus anatomy [3]. EN-DCR by an endonasal approach was first described over 120 years ago $[8,9]$. However, during its early days, this approach failed to gain popularity due to lack of technology to allow a good access to the nasal cavity. As a result of the development of fine nasal surgical instruments, interest in this approach has surged in the last two decades. EN-DCR through the nasal cavity with the aid of an endoscope become very popular [10]. More and more research is being focused on the application of EN-DCR, both for primary surgery and for revising failed cases [9,11,12]. Satisfactory results in treating acryocystitis using EN-DCR have been achieved in the last decade, with the reported success rate ranging from $81.2 \%$ to $100 \%$ [13-18], which is comparable to that of EX-DCR. EN-DCR also has the advantages of significantly shortened operation time, better patient satisfaction, and the avoidance of an external scar [19]. Although EN-DCR has been used since the 1990s in China, most of the studies on this procedure have been done outside of China [20]. There is a lack of multi-center studies to evaluate its effectiveness in the Chinese adult population. This study reviewed 185 cases of EN or EX-DCR, performed by 3 surgeons from 3 hospitals in the different areas of China, with a 1-year follow-up. The surgical techniques, primary outcomes, and final outcomes are compared.

\section{Patients and Methods}

\section{Study Design}

A retrospective multi-center case series was conducted, with 112 EN-DCR procedures out of 102 patients and 73 EX-DCR procedures out of 65 patients. These patients were evaluated and the data were collected using charts and hospital records from Eye Hospital of Wenzhou Medical University, Jiaxing Traditional Chinese Medicine Hospital and the First Hospital of Qiqihar City, with a focus on age, gender, clinical presentation, previous procedures, surgery types, operation time, and symptoms at each follow- up and ENDCR procedure revision.

\section{Ethic Approval}

The study was carried out in accordance with the ethical guidelines of the Declaration of Helsinki.

An Institutional Review Board (IRB) approval was obtained from the IRB committee at The First Hospital of Qiqihar City.

\section{Inclusion Criteria}

Patients included in this study had to meet the following criteria: seeing primarily or referred by ophthalmologists to the three tertiary care regional hospitals from Jan to Dec 2016, being eighteen years

of age or older, diagnosed as having either acute or chronic dacryocystitis respectively, and having follow-up time of more than three months.

\section{Exclusion Criteria}

We excluded patients with evidence of any of the canalicular obstruction, lacrimal sac tumor, dacryolith, or traumatic lacrimal duct obstruction. Patient who had previously been treated by surgical methods on any eye or died during the follow-up time were also excluded.

\section{Processes of the Two Approaches}

All patients were well informed about the advantages and disadvantages of the EX-DCR and EN-DCR methods. The type of the surgical approach was decided by the patients. All the patients were under local anesthesia. The EX and EN-DCRs were performed with a standardized surgical procedure, as described in detail by Duwal and Saiju [21] with minor modifications. The differences from the description of EX-DCR were that the posterior flaps of the lacrimal sac and the suture of nasal mucosa. A silicone stent was placed in the lacrimal sac in the operation. The nasal mucosa was sutured with a 6-0 absorbable suture. The differences from the ENDCR were that a "U" or "]" shaped pedicled mucosa flap was formed. A $2.5 \mathrm{~mm}$ curved diamond DCR Burr attached to a microdebrider (XPS3000, Medtronic Xomed, Minneapolis, MN, USA) was used to thin the frontal process of the maxilla. A bony window was created by Kerrison rongeur, about $12 \mathrm{~mm}$ diameter. The nasal mucosa flap was completely removed, partially removed, or preserved, and the residual exposed bone surface was covered. The lacrimal sac was filed with different supports, which were chosen based on the intraoperative conditions and the surgeons.

\section{Postoperative Care and Follow-Up}

A topical combination of steroids and antibiotic eye drops was used for a week in the operated eye. The lacrimal duct was irrigated 3 times in the first week and when he or she followed up after operation. Endoscopy was performed at each visit, to confirm the patency of the lacrimal passage and rehabilitation of the nasal anatomy. Saline nasal spray was applied for nasal mucosal decongestion twice every day for 1 week. The silicone stent was removed at 2-3 months in both approaches. Outpatient clinic follow-up was regularly received at least 3-12 months (average 9.7 months).

\section{Definition of Success [22]}

Surgical outcome was graded at the 1-year follow-up check. Complete success was defined as the total resolution of symptoms, no infection re-occurrence, and no tearing or discharge after surgery. Partial success was defined as evidence of minor intermittent tearing with significant improvement, in comparing with 
preoperative status. Anatomical success was defined as complete success plus partial success. Surgical failure meant that the patient had persistent or recurrent tearing. Getting an anatomical success without any revision surgery was defined as the primary surgical success. Getting an anatomical success after surgeries (including repeated surgeries) was defined as the final surgical success.

\section{Data Collection}

The data collection was completed between March and May 2018. The data collection forms included demographic variables, indications, background diseases (systemic and ocular), duration of epiphora Surgical outcome, revision and symptoms at each follow-up. Three experience ophthalmologists with master's degrees, each from each of three regional hospitals, were asked to review and collect data using the data collection forms. Before data collecting for the study, 5 cases were allowed to collect for each ophthalmologist as the pilot collection. The information was presented by the principle investigator (PI) in an internet conference to explain each item of the form of this study as well as for questions and answers.

\section{No in-Person Follow-up}

Patients who did not revisit the hospital were reviewed by the surgeons by the telephone follow-ups, based on the recorded information.

\section{Data Analysis}

Statistical Product and Service Solutions (SPSS, Chicago, IL, USA) version 19.0 was used to analyze the data. Kaplan-Meier survival analysis was used to compare the primary success rate of the two methods. The 2 analysis was used for comparing the categorical variables, and t-tests were used for comparing continuous variables. Odds ratios were calculated to predict the odds in operating success of different techniques in EN-DCR. A P value of 0.05 was considered as the significant difference.

\section{Results}

\section{Basic Data}

The Primary Success Rate between Different Surgeries: For this retrospective study, a total of 112 eyes out of 102 patients who underwent EN-DCR and 73 eyes out of 65 patients who underwent EX-DCR were enrolled. There was no statistical significant difference in constituent ratio of age, sex, type of dacryocystitis and systemic comorbidity between the two groups. There was no statistical difference in surgical outcomes between these two surgeries with chi-square test, the 2 value was 0.501 for EN-DCR and 0.921 for EXDCR with both of the $P$ values $\geq 0.05$. The demographics, comparison of the two groups, and success rates of the three surgeons are listed in Table 1 and Table 2.

Table 1: Demographics of 102 patients who underwent 112 EN-DCR and 65 patients with 73 EX-DCR procedures.

\begin{tabular}{|c|c|c|c|c|}
\hline Characteristics & EN-DCR $(n=102)$ & EX-DCR $(n=65)$ & 2 & $P$ value \\
\hline Age (year) & & & 5.462 & 0.362 \\
\hline $21 \sim 30$ & 5 & 1 & & \\
\hline $31 \sim 40$ & 8 & 3 & & \\
\hline $41 \sim 50$ & 22 & 19 & & \\
\hline $51 \sim 60$ & 30 & 25 & & \\
\hline $61 \sim 70$ & 30 & 15 & & \\
\hline $71 \sim 80$ & 7 & 2 & & \\
\hline Sex & & & 0.259 & 0.611 \\
\hline Male & 10 & 8 & & \\
\hline Female & 92 & 57 & & \\
\hline Type of dacryocystitis & & & 0.689 & 0.407 \\
\hline Chronic dacryocystitis & 92 & 61 & & \\
\hline Acute dacryocystitis & 10 & 4 & & \\
\hline Side of eyes & & & 0.723 & 0.697 \\
\hline Only right eye & 58 & 34 & & \\
\hline Only left eye & 34 & 22 & & \\
\hline Bilateral eyes & 10 & 9 & & \\
\hline Systemic comorbidity & & & 0.407 & 0.982 \\
\hline Hypertension & 10 & 6 & & \\
\hline Diabetes & 7 & 3 & & \\
\hline coronary insufficiency & 16 & 10 & & \\
\hline cerebral ischemic stroke & 3 & 2 & & \\
\hline none & 66 & 44 & & \\
\hline
\end{tabular}


Table 2: The primary success rate between different surgeons.

\begin{tabular}{|c|c|c|c|c|c|c|c|c|}
\hline \multirow{2}{*}{$\begin{array}{c}\text { Success } \\
\text { rate }\end{array}$} & \multicolumn{9}{|c|}{ EN-DCR (n=112) } & \multicolumn{4}{c|}{ EX-DCR (n=73) } \\
\cline { 2 - 10 } & $\begin{array}{c}\text { Anatomical } \\
\text { Success }\end{array}$ & $\begin{array}{c}\text { Surgical } \\
\text { failure }\end{array}$ & 02 & P & $\begin{array}{c}\text { Anatomical } \\
\text { success }\end{array}$ & $\begin{array}{c}\text { Surgical } \\
\text { failure }\end{array}$ & ?2 & P \\
\hline 1 & 37 & 6 & 1.062 & 0.588 & 22 & 2 & 0.290 & 0.865 \\
\hline 2 & 34 & 4 & & & 16 & 2 & & \\
\hline 3 & 29 & 2 & & & 27 & 4 & \\
\hline
\end{tabular}

Duration of Symptoms before Operation: The mean time (SD) of epiphora before operation for the EN-DCR and EX-DCR patients was 6.26 (5.93) ears and 7.06 (7.24) years, respectively. The mean time (SD) of purulent discharge before operation for the EN-DCR and EX-DCR patients was 4.50 (4.95) years and 3.61(5.52) years, respectively. The mean time (SD) of erythema and swelling before operation for the EN-DCR and EX-DCR patients was 4.86

Table 3: Duration of symptoms before operation.
(1.86) days and 5.03(3.46) days, respectively. There was no statistical, significant difference in duration of symptoms before operation (Table 3). The mean operation time (SD) for the EN-DCR patients was 33.90 (5.58) minutes, and 53.19 (13.76) minutes for the EX-DCR patients. The independent t-test shows that the $t$ value was 11.88, with the P value $<0.001$.

\begin{tabular}{|c|c|c|c|c|}
\hline Group & EN-DCR (n=112) & EX-DCR (n=73) & t & P \\
\hline Eymptom & $6.26 \pm 5.93$ & $7.06 \pm 7.24$ & 0.715 & 0.476 \\
\hline Purulent discharge (year) & $4.50 \pm 4.95$ & $3.61 \pm 5.52$ & 0.963 & 0.337 \\
\hline Erythema and swelling(day) & $4.86 \pm 1.86$ & $5.03 \pm 3.46$ & 0.087 & 0.104 \\
\hline
\end{tabular}

Probability of Primary Success for EN-DCR with Different Techniques: For patients who accepted EN-DCR as the primary treatment, the odds ratios (ORs) of anatomical success were 6.628 for patients with ethmoid sinus incision compared to patients without ethmoid sinus incision $(\mathrm{P}<0.05)$; 12.25 for patients with
Miller gel as support compared to those who had with silicone stents $(\mathrm{P}<0.05)$; 6.667 for patients with partly preserved nasal mucosa compared to patients without preserved nasal mucosa $(\mathrm{P}$ $<0.05)$ Table 4.

Table 4: Probability of primary success for EN-DCR with different techniques (*Reference group).

\begin{tabular}{|c|c|c|c|c|}
\hline Variable & Anatomical success (\%) & Surgical failure (\%) & Odds ratio & $\mathbf{P}$ \\
\hline \multicolumn{5}{|l|}{ Ethmoid sinus incision } \\
\hline without* & 43 (38.39) & $10(8.93)$ & 1 & \\
\hline with & $57(50.89)$ & $2(1.79)$ & 6.628 & 0.018 \\
\hline \multicolumn{5}{|l|}{ Support } \\
\hline Silicone stents* & $12(10.71)$ & $3(2.68)$ & 1 & \\
\hline Miller gel & $49(43.25)$ & $1(0.89)$ & 12.25 & 0.036 \\
\hline Miller gel plus stent & 17 (15.18) & $1(0.89)$ & 4.25 & 0.234 \\
\hline Gelatin sponge & $5(4.46)$ & $1(0.89)$ & 1.25 & 0.861 \\
\hline Vaseline gauze & $8(7.14)$ & $2(1.79)$ & 1 & 1 \\
\hline Expansive sponge & $9(8.04)$ & $4(3.57)$ & 0.563 & 0.514 \\
\hline \multicolumn{5}{|l|}{ Nasal mucosa } \\
\hline Not preserved* & $13(11.61)$ & $4(3.57)$ & 1 & \\
\hline Partly preserved & $65(58.04)$ & $3(2.68)$ & 6.667 & 0.021 \\
\hline Completely preserved & $22(19.64)$ & $5(4.46)$ & 1.354 & 0.689 \\
\hline Total & $100(89.29)$ & $12(10.71)$ & & \\
\hline
\end{tabular}

The Primary Success Rate of the Two Methods: Table 5 summarizes primary surgical outcomes at 1 year after surgery. Complete success was achieved in 87.5\% (98/112) of EN-DCR patients and $86.30 \%(63 / 73)$ of EX-DCR patients. Partial success was recorded in $1.79 \%(2 / 112)$ of EN-DCR patients and $2.74 \%$ (2/73) of EX-DCR patients, so the total primary surgical success rate was recorded as $89.29 \%$ (100/112) for EN-DCR and $89.04 \%$ $(65 / 73)$ for EX-DCR. 
Table 5: The primary success rate of the two methods.

\begin{tabular}{|c|c|c|c|c|c|c|c|c|c|c|}
\hline \multirow[b]{2}{*}{$\begin{array}{l}\text { Effect } \\
\text { Time }\end{array}$} & \multicolumn{4}{|c|}{ EN-DCR $(n=112)$} & \multicolumn{4}{|c|}{ EX-DCR $(n=73)$} & \multirow[b]{2}{*}{$\mathbf{X}^{2}$} & \multirow[b]{2}{*}{$\mathbf{P}$} \\
\hline & $\begin{array}{c}\text { Complete } \\
\text { success } \\
(\%)\end{array}$ & $\begin{array}{c}\text { Partial } \\
\text { success } \\
(\%)\end{array}$ & $\begin{array}{l}\text { Anatomical } \\
\text { success } \\
(\%)\end{array}$ & $\begin{array}{c}\text { Surgical } \\
\text { Failure } \\
(\%)\end{array}$ & $\begin{array}{c}\text { Complete } \\
\text { success } \\
(\%)\end{array}$ & $\begin{array}{c}\text { Partial } \\
\text { success } \\
(\%)\end{array}$ & $\begin{array}{c}\text { Anatomical } \\
\text { success } \\
(\%)\end{array}$ & $\begin{array}{c}\text { Surgical } \\
\text { Failure } \\
(\%)\end{array}$ & & \\
\hline $1 \mathrm{~W}$ & 108(96.43) & $4(3.57)$ & $112(100)$ & $0(0)$ & $67(91.78)$ & $5(6.85)$ & $72(98.63)$ & $1(1.37)$ & 2.611 & 0.271 \\
\hline $1 \mathrm{M}$ & 101(90.18) & $5(4.46)$ & $106(94.64)$ & $6(5.36)$ & $65(89.04)$ & $4(5.48)$ & $69(94.52)$ & $4(5.48)$ & 0.101 & 0.951 \\
\hline $3 \mathrm{M}$ & $99(88.39)$ & $3(2.68)$ & 102(91.07) & $10(8.93)$ & $63(86.30)$ & $3(4.11)$ & $66(90.41)$ & $7(9.59)$ & 0.322 & 0.851 \\
\hline $6 \mathrm{M}$ & $98(87.50)$ & $3(2.68)$ & 102(91.07) & $11(9.82)$ & $63(86.30)$ & $3(4.11)$ & $66(90.41)$ & $7(9.59)$ & 0.289 & 0.866 \\
\hline $9 \mathrm{M}$ & $98(87.50)$ & $2(1.79)$ & $100(89.29)$ & $12(10.71)$ & $63(86.30)$ & $3(4.11)$ & $66(90.41)$ & $7(9.59)$ & 0.945 & 0.623 \\
\hline $12 \mathrm{M}$ & $98(87.50)$ & $2(1.79)$ & $100(89.29)$ & $12(10.71)$ & $63(86.30)$ & $2(2.74)$ & $65(89.04)$ & $8(10.96)$ & 0.196 & 0.907 \\
\hline
\end{tabular}

The Final Success Rate of the Two Methods and Result rates of the EN-DCR and EX-CR groups after repeat EN-DCR were of Revision EN-DCR for the Patient with Surgical Failure of $97.32 \%$ and $97.26 \%$, respectively. There was a significant statistical Primary Treatment: A repeated EN-DCR was accepted by the difference compared to primary surgery success rate (89.29\% and patients with primary surgical failures in both the EN-DCR (12/12) $\quad 89.04 \%$, respectively) Table 7.

and EX-DCR (8/9) group (Table 6). The final surgery success

Table 6: Result of revision EN-DCR for the patient with surgical failure of primary treatment.

\begin{tabular}{|c|c|c|c|c|}
\hline Items & Surgical failure patients & Accepted revision EN-DCR & $\begin{array}{c}\text { Anatomical success after } \\
\text { revision EN-DCR }\end{array}$ & $\begin{array}{c}\text { Failure after revision } \\
\text { EN-DCR }\end{array}$ \\
\hline Number in EN-DCR group & 12 & 12 & 9 & 3 \\
Number in EX-DCR group & 8 & 7 & 5 & 2 \\
\hline
\end{tabular}

Table 7: The final success rate of the two methods.

\begin{tabular}{|c|c|c|c|c|c|c|c|c|c|c|c|c|}
\hline Group & $\begin{array}{l}\text { EN-DCR } \\
(n=112)\end{array}$ & & & & 回2 & $\mathbf{P}$ & $\begin{array}{l}\text { EX-DCR } \\
(n=73)\end{array}$ & & & & 国2 & $\mathbf{P}$ \\
\hline Index & $\begin{array}{c}\text { Complete } \\
\text { success } \\
(\%)\end{array}$ & $\begin{array}{c}\text { Partial } \\
\text { success } \\
(\%)\end{array}$ & $\begin{array}{c}\text { Anatomical } \\
\text { success } \\
(\%)\end{array}$ & $\begin{array}{c}\text { Surgical } \\
\text { Failure } \\
(\%)\end{array}$ & & & $\begin{array}{c}\text { Complete } \\
\text { success } \\
(\%)\end{array}$ & $\begin{array}{c}\text { Partial } \\
\text { success } \\
(\%)\end{array}$ & $\begin{array}{c}\text { Anatomical } \\
\text { success } \\
(\%)\end{array}$ & $\begin{array}{c}\text { Surgical } \\
\text { failure } \\
(\%)\end{array}$ & & \\
\hline Primary & $98(87.50)$ & $2(1.79)$ & $100(89.29)$ & $12(10.71)$ & 5.788 & 0.016 & $63(86.30)$ & $2(2.74)$ & $65(89.04)$ & $8(10.96)$ & 3.865 & 0.049 \\
\hline Final & $107(95.54)$ & $2(1.79)$ & $109(97.32)$ & $3(2.68)$ & & & $66(90.41)$ & $3(4.11)$ & $71(97.26)$ & $2(2.74)$ & & \\
\hline
\end{tabular}

Kaplan-Meier Survival Plot: A Kaplan-Meier survival plot was drawn to compare the primary success of the two methods (Figure 1). All patients suffering acute dacryocystitis in both of the groups were cured after primary surgeries. The Kaplan-Meier survival

analysis shows that the log rank $\mathrm{x} 2$ was 0.369 , with a $\mathrm{P}$ value of 0.543 , indicating no statistical difference in surgical outcomes between these two groups.

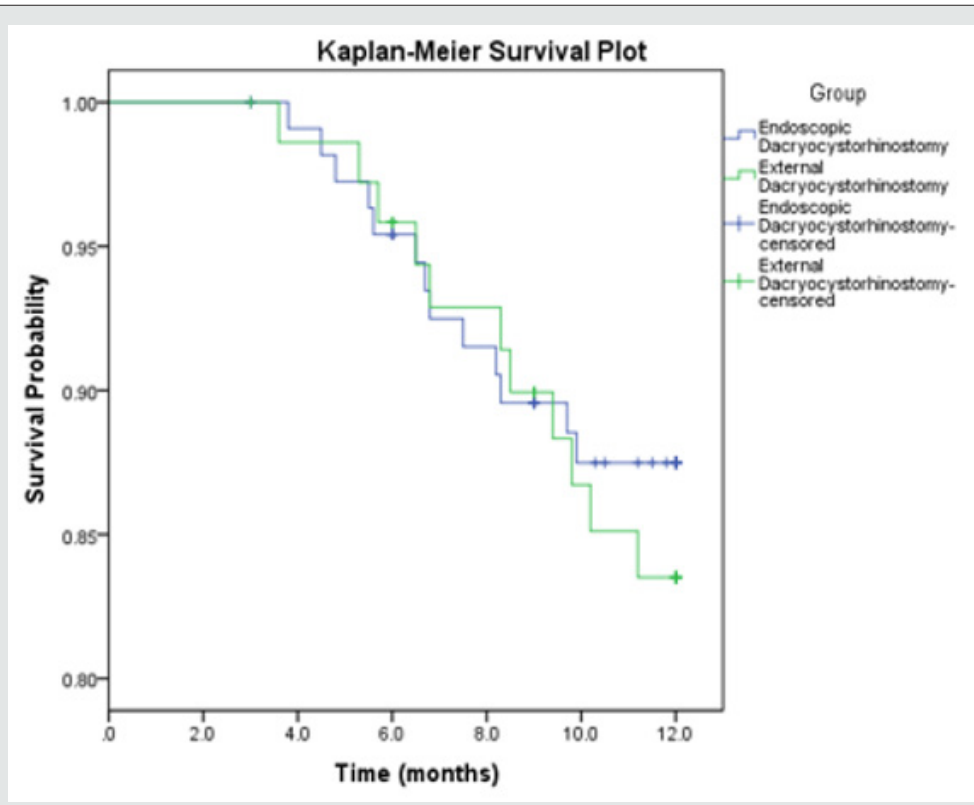

Figure 1: A Kaplan-Meier survival analysis plot of the primary surgical success rate between the EN and EX-DCR groups. 


\section{Discussion}

Both acute and chronic dacryocystitis are very painful conditions. Because they resolve slowly with systemic antibiotics, [23-25], they usually end up with DCR. EX-DCR was considered as the gold standard for treatment of dacryocystitis traditionally, with the advantages under direct visualization, no need for expensive instrumentation, and the capability to form and suture flaps between the lacrimal sac and nasal mucosa. However, it does have its disadvantages, including a medial canthal scar and disruption of the pumping mechanism of the orbicularis muscles. EN-DCR is gaining a wider acceptance as a promising method of management [26] in some metro capitals of China [27]. The advantages of EN-DCR are its less invasive nature, shorter operation time and preservation of pump function of the orbicularis muscle. The absence of external scars and low complication rate has made ENDCR popular [16]. A Study by Prangya Panda et al. [25] indicated that chronic dacryocystitis is more common in females with low socioeconomic status presenting with discharge from the eye for a long period of time. In our study, the majority of victims of both chronic and acute dacryocystitis were women. Although all the patients were fully informed of the advantages and disadvantages of the two methods before operation, some patients still had to choose EX-DCR because of its lower medical cost in China, therefore we had the opportunity to compare the effect of the two approaches in the Chinese adult population. In our cohort, all patients were followed up monthly until the 3rd month, and every 3 months after the 3rd month for one year. All patients were examined under endoscopy during follow-up. If the patient could not come or refused to come to the hospital for examination, the telephone follow-up records were referred in the primary success rate analysis of the two methods. However, in our Kaplan-Meier Survival analysis, the telephone follow-up-outcome was defined as the missing. In our multi-centered retrospective study, we compared the primary surgical success rate between the EN and EX-DCR groups through Kaplan-Meier survival analysis (Figure 1). The primary surgical success rate of EN and EX-DCR (89.29\% and 89.04\%, respectively, $\mathrm{P}>0.05$ ) were similar to most of the reports.

A study by Emmy Y et al. [28] indicated that the success rate of the two approaches was $87.5 \%$. Rajesh SJ et al. [29] stated that the success rate of the conventional group was $82.1 \%$ and in the endonasal group was $89.7 \%$ in treating acute dacryocystitis. These reports are slightly higher than the report of $84 \%$ for EN-DCR versus $70 \%$ for EX-DCR from Jain B et al. [16] in treating chronic daryocystitis. However, comparing published success rates of lacrimal surgery is a difficult task because of the different criteria [30], and the different skill levels of the surgeons. We did not compare the success rate of the two approaches in treating acute and chronic dacryocystitis separately because of the small sample size with acute dacryocystitis in the two groups (10 and 4, relatively for EN-DCR and EX-DCR group). For the patients treated by EXDCR, an extra period of systemic antibiotic prior to the operation may have caused the patients to suffer from longer, more painful symptoms than those treated by EN-DCR [31,32]. In our study, all operations were carried out after the patients' admission to the wards. For the acute dacryocystitis, the traditional resolve methods are systemic antibiotics, hot compress, surgical incision and drainage. When acute infection has subsided, subsequent external dacryocystorhinostomy as done. However, this was not contraindicated in the EN-DCR procedures, because we carried out the procedure directly when the acute dacryocystitis happened [33]. So, the median durations from admission to surgery were 1 (range: 1 2) and 3 (range: 2 5) days relatively for EN-DCR and EX-DCR, respectively. Patients with primary surgery failure in both of the groups were all suffering from chronic dacryocystitis. They all denied repeated EX-DCR because of its invasive nature;

Whereas the endoscopic approach was more easily accepted by patients for revision. Several studies indicated the excellent performance of EN-DCR in revision with no residual effects [3437]. In this study, twelve patients from the EN-DCR group accepted repeated EN-DCR. The revision of three patients did not achieve the resolution, because of small fibrosed and adhesive sac. Of the eight patients with surgical failure of primary EX-DCR, seven accepted EN-DCR in revision and six achieved anatomical success. Only one did not success because of small and adhesive lacrimal sac. One patient refused repeated surgery because of the cost and as followed up regularly with sac syringing at each visit (Table 6). In summary, the application of EN-DCR in revision was effective and readily accepted by the patients. As a multicenter study, three surgeons were involved. Although the general success rate of the different surgeons in this study was comparable in both of the groups, each surgeon did prefer slightly different techniques, which affected the result of the surgery $[14,38]$. In the EN-DCR group in this study, the odd ratio of anatomic success was 6.628 for patients with ethmoid sinus incision compared to patients without (Table 4). The add ratio was 12.25 for patients with Miller gel as compared to those who were with silicone stents. The ratio was 6.667 for patients with partly preserved nasal mucosa compared to patients without preserved nasal mucosa. Therefore, further research, especially randomized contrast trials, are merited to investigate techniques for higher success rates using EN-DCR.

\section{Conclusion}

In conclusion, this multicentered retrospective study indicated that EN-DCR was a valid alternative to external procedure in the treatment of dacryocystitis in Chinese adult population because of the comparable primary success rate to external approach and the unique advantages in treating the patients that need repeated surgeries.

\section{References}

1. Taylor RS, JV Ashurst (2017 Dacryocystitis.

2. Badhu B, Dulal S, Kumar S, Thakur SK, Sood A, et al. (2005) Epidemiology of chronic dacryocystitis and success rate of external dacryocystorhinostomy in Nepal. Orbit 24(2): 79-82.

3. Naraghi M, Mohammadi SZT, Sontou AF, Deroee AF, Boroojerdi M (2012) Endonasal endoscopic dacryocystorhinostomy: how to achieve optimal results with simple punch technique. Eur Arch Otorhinolaryngol 269(5): 1445-1449.

4. Taskin U, Yigit O, Sisman A, Eltutar K, Eryigit T (2011) Comparison of outcomes between endoscopic and external dacryocystorhinostomy with a Griffiths nasal catheter. J Otolaryngol Head Neck Surg 40(3): 216220. 
5. Emmerich KH, Busse H, Meyer Rüsenberg HW (1994) Dacryocystorhinostomia externa. Technique, indications and results. Der Ophthalmologe: Zeitschrift der Deutschen Ophthalmologischen Gesellschaft 91(3): 395-398.

6. Tarbet KJ, Custer PL (1995) External dacryocystorhinostomy: surgical success, patient satisfaction, and economic cost. Ophthalmology 102(7): 1065-1070.

7. Kashkouli MB, Parvaresh MM, Modarreszadeh M, Hashemi M, Beigi B (2003) Factors affecting the success of external dacryocystorhinostomy. Orbit 22(4): 247-255.

8. Toti A (1904) Nuovo metodo conservatore dicura radicale delle soppurazioni croniche del sacco lacrimale (dacriocistorinostomia). Clin Moderna 10: 385-387.

9. Massaro BM, Gonnering RS, Harris GJ (1990) Endonasal laser dacryocystorhinostomy: A new approach to nasolacrimal duct obstruction. Archives of ophthalmology 108(8): 1172-1176.

10. Rabina G, Golan S, Neudorfer M, Leibovitch I (2013) External dacryocystorhinostomy: Characteristics and surgical outcomes in patients with and without previous dacryocystitis. Journal of ophthalmology 2013: pp. 287524.

11. Mc Donogh M, Meiring JH (1989) Endoscopic transnasal dacryocystorhinostomy. The Journal of Laryngology \& Otology 103(6): 585-587.

12. Marcet MM, Kuk AK, Phelps PO (2014) Evidence-based review of surgical practices in endoscopic endonasal dacryocystorhinostomy for primary acquired nasolacrimal duct obstruction and other new indications. Current opinion in ophthalmology 25(5): 443-448.

13. Das SK, Sarkar P, Dan A, Boral K, Basak B, et al. (2013) Endoscopic dacryocystorhinostomy: A study at IPGMER, Kolkata. Indian Journal of Otolaryngology and Head \& Neck Surgery 65(2): 366-370.

14. Mueller SK, Freitag SK, Lefebvre DR, Bleier BS (2018) Endoscopic DCR using bipedicled interlacing mucosal flaps. The Laryngoscope 128(4): 794-797.

15. Tu Y, Qian Z, Zhang J, Wu W, Xiao T (2015) Endoscopic endonasal dacryocystorhinostomy combined with canaliculus repair for the management of dacryocystitis with canalicular obstruction. Journal of ophthalmology 2015: 657909.

16. Jain B, Adgaonkar N (2014) Comparison of modified conventional DCR with endonasal DCR. Journal of Evolution of Medical and Dental Sciences 3(53): 12358-12361.

17. Herzallah I, Alzuraiqi B, Bawazeer N, Marglani O, Alherabi A, et al. (2013) Results of endoscopic endonasal dacryocystorhinostomy. The Journal of craniofacial surgery 24(1): e11-2.

18. Herzallah I, Alzuraiqi B, Bawazeer N, Marglani O, Alherabi A, et al (2015) Endoscopic Dacryocystorhinostomy (DCR): A comparative study between powered and non-powered technique. J Otolaryngol Head Neck Surg 44(1): p. 56.

19. Gauba V (2014) External versus endonasal dacryocystorhinostomy in a specialized lacrimal surgery center. Saudi Journal of Ophthalmology 28(1): 36-39.

20. Bing Z, Xin T (1994) Endoscopic transnasal dacryocystorhinostomy: Results in 35 cases. Chinese Archives of Otolaryngology-Head and Neck Surgery 1(2): 80-83.

21. Duwal S, Saiju R (2015) Outcomes of external dacryocystorhinostomy and endoscopic endonasal dacryocystorhinostomy in the management of nasolacrimal duct obstruction. Nepalese Journal of Ophthalmology $7(1): 39-46$.
22. Coumou AD, Genders SW, Smid TM, Saeed P (2017) Endoscopic dacryocystorhinostomy: Long term experience and outcomes. Acta ophthalmologica 95(1): 74-78.

23. Cahill KV, Burns JA (1993) Management of acute dacryocystitis in adults. Ophthalmic plastic and reconstructive surgery 9(1): 38-41.

24. Dolman PJ (2003) Comparison of external dacryocystorhinostomy with non-laser endonasal dacryocystorhinostomy. Ophthalmology 110(1): 78-84.

25. Panda P, Sadangi BK, Jena D (2017) A study on clinical evaluation of chronic dacryocystitis. International Journal of Research in Medical Sciences 5(6): 2684-2686.

26. Wu W, Yan W, MacCallum JK, Tu Y, Jiang AC, et al. (2009) Primary treatment of acute dacryocystitis by endoscopic dacryocystorhinostomy with silicone intubation guided by a soft probe. Ophthalmology 116(1): 116-122.

27. Thiagarajan B, Koth S (2014) Laying the Tears Highway-A Drive through Endo-Dcr. Otolaryngology online journal 4(2): 65-85.

28. Li EY, Wong ES, Wong AC, Yuen HK (2017) Primary vs Secondary Endoscopic Dacryocystorhinostomy for Acute Dacryocystitis With Lacrimal Sac Abscess Formation: A 15 Randomized Clinical Trial. JAMA ophthalmology 135(12): 1361-1366.

29. Joshi RS, Deshpande AS (2017) Success rate of conventional dacryocystorhinostomy in post-acute dacryocystitis compared to endonasal dacryocystorhinostomy in acute dacryocystitis. Journal of ophthalmic \& vision research 12(3): 290-295.

30. Gibbs DC (1967) New probe for the intubation of lacrimal canaliculi with silicone rubber tubing. The British journal of ophthalmology 51(3): 198.

31. Jain S, Ganguly A, Singh S, Mohapatra S, Tripathy D, etal. (2017) Primary no endoscopic endonasal versus delayed external dacryocystorhinostomy in acute dacryocystitis. Ophthalmic Plastic \& Reconstructive Surgery 33(4): 285-288.

32. Pinar Sueiro S, Sota M, Lerchundi TX, Gibelalde A, Berasategui B, et al. (2012) Dacryocystitis: Systematic approach to diagnosis and therapy. Current infectious disease reports 14(2): 137-146.

33. Lee TS, Woog JJ (2001) Endonasal dacryocystorhinostomy in the primary treatment of acute dacryocystitis with abscess formation. Ophthalmic Plastic \& Reconstructive Surgery 17(3): 180-183.

34. Reddy NV, Kumari KA, Shankar T, Kumar M, Majeed J (2015) Revision endoscopic DCR surgeries: our experience. surgery 6: 7.

35. Bharangar S, Singh N, Lal V (2012) Endoscopic Endonasal Dacryocystorhinostomy: Best Surgical Management for DCR. Indian Journal of Otolaryngology and Head \& Neck Surgery 64(4): 366-369.

36. Mahajan GD, Shah P, Thomas J, Ghate G, Ingale M, et al. (2014) Retrospective study of 861 cases of Endoscopic Endonasal DCR: Our experience. Journal of Evolution of Medical and Dental Sciences 3(9): 2121-2126.

37. Hull S, Lalchan SA, Olver JM (2013) Success rates in powered endonasal revision surgery for failed dacryocystorhinostomy in a tertiary referral center. Ophthalmic Plastic \& Reconstructive Surgery 29(4): 267-271.

38. Kumar R, Batni G, Bharke S (2018) Comparison of Endonasal DCR Surgery Using Cautery and Surgical Blade Technique in Cases of Chronic Dacryocystitis. Indian Journal of Otolaryngology and Head \& Neck Surgery 70(2): 295-298. 
(C) (i) This work is licensed under Creative To Submit Your Article Click Here:

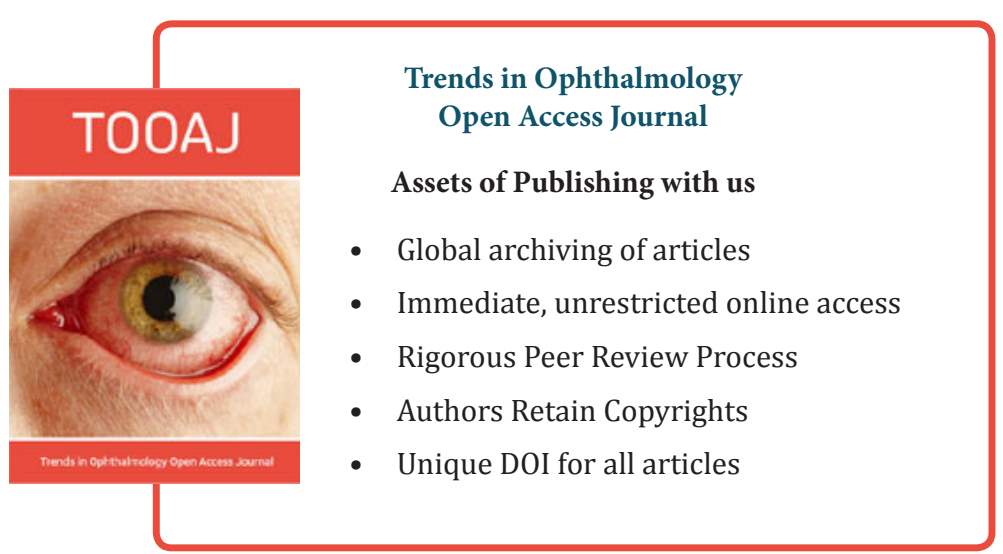

